\title{
Association of seasonal reproductive patterns with changing food availability in an equatorial carnivore, the spotted hyaena (Crocuta crocuta)
}

\author{
K. E. Holekamp ${ }^{1}$, M. Szykman ${ }^{1}$, E. E. Boydston ${ }^{1}$ and L. Smale ${ }^{2}$ \\ Departments of ${ }^{1}$ Zoology and ${ }^{2}$ Psychology, Michigan State University, East Lansing, MI 48824, USA
}

\begin{abstract}
Reproductive seasonality was examined in an equatorial population of free-living spotted hyaenas (Crocuta crocuta) in Kenya. The study population was observed continuously for 10 years, during which time the dates of all births, conceptions, weanings, and cub deaths were recorded. Local prey abundance was estimated two to four times per month, and rainfall was recorded daily throughout the study period. Births occurred during every month of the year, but a distinct trough in births occurred from February to May. This trough occurred approximately one gestation period after the phase of the annual cycle during which prey animals were least abundant in the home range of the hyaenas, and conceptions occurred most frequently when food abundance was greatest. Neither rainfall nor cub mortality were correlated with births or conceptions. Thus, although spotted hyaenas are capable of breeding throughout the year, they exhibit a moderate degree of seasonality that most likely reflects responses to seasonal variation in energy availability.
\end{abstract}

\section{Introduction}

Spotted hyaenas (Crocuta crocuta) are large, gregarious carnivores that occur throughout much of sub-Saharan Africa, from approximately $28^{\circ} \mathrm{S}$ of the equator to approximately $17^{\circ}$ N (Mills, 1990; Estes, 1991). In most populations studied to date, births occur throughout the year, but in many of these populations, patterns of births include distinct seasonal peaks or troughs (Smithers, 1966; Kruuk, 1972; Lindeque and Skinner, 1982; Frank, 1986; Mills, 1990). The environmental factors that account for reproductive seasonality in this species are unknown. In the present study, reproductive data were obtained over 10 years from one large Crocuta clan inhabiting a tropical grassland in eastern Africa. The aims of the study were to determine whether reproduction varies seasonally in this population and, if it does, to identify the environmental factors that might promote such seasonality.

\section{Materials and Methods}

\section{Study population}

The study site was the Talek area of the Masai Mara National Reserve, in southwest Kenya, situated at $1^{\circ} 40^{\prime} \mathrm{S}$, $35^{\circ} 50^{\prime} \mathrm{E}$, at a mean elevation of $1575 \mathrm{~m}$ above sea level. This is an area of open, rolling grasslands grazed year round by large concentrations of several different ungulate species, the most numerous of which are Thomson's gazelle (Gazella

Received 22 July 1998. thomsonii), topi (Damiscilus korrigum) and impala (Aepyceros melampus). Each year, these resident antelope populations are joined for 3-4 months by large migratory herds of wildebeest (Connochaetes taurinus) and zebra (Equus burchelli). The migratory herds typically arrive in the Talek area in June or July and depart in September. Maximum temperatures in this ecosystem are $27-28^{\circ} \mathrm{C}$ in every month of the year, and minimum temperatures vary from $13^{\circ}$ to $16^{\circ} \mathrm{C}$ (Sinclair, 1995). In contrast to these constant temperatures, rainfall varies greatly from month to month (Sinclair, 1979).

The subject population was one large Crocuta clan inhabiting a home range of approximately $65 \mathrm{~km}^{2}$. The Talek study clan usually contained $20-23$ breeding females, $10-12$ adult immigrant males, and $30-40$ cubs and subadults. Cubs were $<12$ months old, and subadults were older individuals that had not yet reached reproductive maturity. All hyaenas in the study clan were known individually by their unique spots, and their sex was determined from the dimorphic glans morphology of the erect phallus (Frank et al., 1990). From June 1988 to April 1998, observers monitored hyaenas in the study area 23-31 days per month, except during April 1991, when Talek hyaenas were observed for only 14 days.

Assignment of dates for births, deaths, conceptions and weanings

In postpubertal male Crocuta, the testes are constantly large and descended, testicular histology does not vary seasonally (Lindeque and Skinner, 1982) and, therefore, fertilizations can occur throughout the year. Female Crocuta 
bear their litters in isolated natal dens, and then transfer them to a communal den when cubs are $2-5$ weeks old. When cubs were first observed here, at natal or communal dens, their ages were estimated to \pm 7 days on the basis of their pelage, size and other aspects of their appearance and behaviour (for example, folded ears, callous pads on carpals, motor coordination). Birth dates were assigned to litters on this basis. Since the duration of gestation is 110 days (Schneider, 1926; Kruuk, 1972), conception dates were calculated by subtracting 110 days from birth dates. Conceptions were inferred exclusively from parturitions, and so conceptions resulting in failed implantation or embryo resorption could not be measured. The date on which any cub was last seen was assigned as its date of death. All hyaenas disappearing before 12 months of age were considered to have died because female Crocuta generally spend their entire lives in their natal groups, and males do not disperse before 2 years of age (Smale et al., 1997).

Weaning conflicts and cessation of nursing indicated when cubs were weaned. Weaning conflicts between cubs and their mothers are easily observed in this species because of the characteristic begging behaviour and loud whining exhibited by cubs at this time. All weaning conflicts were recorded in field notes as critical incidents (Altmann, 1974). In determining weaning dates, all field notes were searched for observations of weaning conflicts and nursing behaviour when mother and cubs were found together. If mother and cub were not found together frequently after the last observed nursing bout, the weaning date was identified as being midway between the last nursing bout and the next sighting of mother and cub together without nursing. However, only intervals of $\leq 20$ days were used in this analysis, so all weaning dates used here were accurate to within \pm 10 days.

\section{Parity of breeding females}

Nulliparous adult females could be distinguished from parous females on the basis of the condition of the pseudopenis. The pseudopenis of a female hyaena is torn when her first litter is born (Frank and Glickman, 1994), leaving a large patch of pink scar tissue on the posterior surface of the phallus. Throughout the current study, the condition of the posterior surface of the phallus in all nulliparous females $\geq 2$ years of age was monitored carefully during the phallic erections commonly exhibited when hyaenas greet each other (Kruuk, 1972; East et al., 1993). Thus, even when the first litter of a female was lost before her cubs first appeared above ground, it was possible to determine reliably ( \pm 10 days) when she had delivered her first litter.

\section{Estimation of prey abundance and rainfall}

Prey abundance in the Talek area was estimated regularly by counting all antelope and zebra found within $100 \mathrm{~m}$ of $4 \mathrm{~km}$ transect lines in two different areas of the home range of the study clan. Both transects were run two to four times each month, between 08:00 and 10:00 h. Ungulate census estimates were averaged for each month of the study. Monthly variation in prey counts has been described by Holekamp et al. (1993). The number of prey animals counted per census ranged from 24 to 4306 , with a mean of $427 \pm 50$ ( $n=240$ censuses). For some analyses, prey abundance each month was divided into five categories on the basis of the mean number of ungulates counted, as follows: $\leq 250$, 251-500, 501-1000, 1001-1500, and > 1500. Throughout the study period, rainfall $(\mathrm{mm})$ was recorded at $24 \mathrm{~h}$ intervals from a rain gauge situated within the home range boundaries of the study clan, and mean monthly rainfall was calculated from daily records over the 10 year study period.

\section{Data analysis}

The number of births, conceptions, weanings and cub deaths were recorded monthly for 113 months. In addition, the percentage of females conceiving litters each month was calculated from the total number of females not currently pregnant $\geq 7$ months after parturition with surviving cubs. Seven months after parturition represents the shortest interval at which any Talek female has been known to conceive her next litter (Holekamp et al., 1996), so this percentage represents the proportion of females with potential to conceive that actually did conceive litters that month. Each of these dependent variables was examined in relation to rainfall and prey availability using analysis of variance (ANOVA). In some analyses, the month of the year was included as a covariate with another independent variable of interest, using analysis of covariance (ANCOVA). Mean values were presented \pm SEM, and differences between groups were considered statistically significant when $P<0.05$.

\section{Results}

\section{Seasonal patterns of births and conceptions}

During the 10 year study period, 145 litters were born to Talek females, and births occurred during every month of the year. The mean number of births occurring each month was $1.21 \pm 0.12$ (range, 0-6), but the number of births varied significantly by month (Fig. 1a; ANOVA: $F=2.047$, $\mathrm{df}=11,102, P=0.031)$. There was a distinct annual trough in births from February to May, during which only $16 \%$ of all births occurred. The number of adult females known to conceive litters each month ranged from 0 to 6 . The number of litters conceived varied significantly by month (Fig. 1b; $F=2.276 ; \mathrm{df}=11,102, P=0.016$ ). Females in this population typically conceive 7-15 months after their last parturition. The percentage of females that were $\geq 7$ months post partum that actually conceived new litters here varied significantly by month $(F=2.210$, df $=11,92, P=0.020)$.

\section{Seasonal patterns of cub mortality}

The timing of births may be influenced by mortality induced by rains or other sources. Rainfall varied significantly 

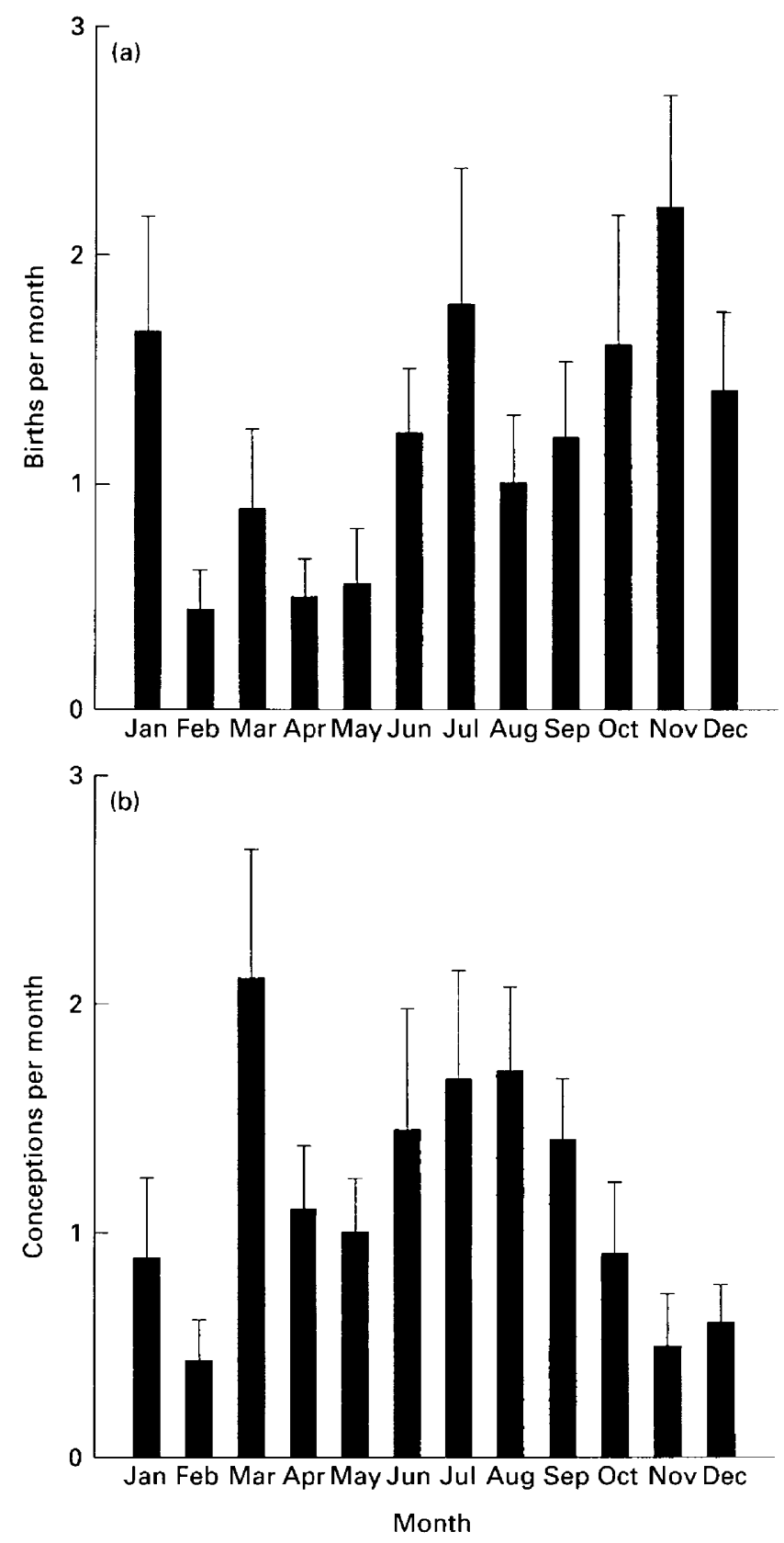

Fig. 1. Mean (+ SEM) number of litters born (a) and conceived (b) each month in the Talek hyaena clan, averaged over 10 years.

from month to month (Fig. 2a; $F=2.482, \mathrm{df}=11,104$, $P=0.008$ ). Because some flooding of hyaena dens was observed during heavy rains, the hypothesis that Crocuta time their births to avoid bearing young during the spring rains was considered. However, neither the number of litters born $(F=0.128, \mathrm{df}=1,101, P=0.721)$ nor the number of litters conceived $(F=0.499 ; \mathrm{df}=1,111, P=0.481)$ in any given month was related to the amount of rain falling during that month, nor was there any significant relationship between the timing of births and early cub mortality. The percentage of all cubs dying during each month of the year varied from
2.2 to $16.1 \%$, but cub mortality did not vary significantly by month ( $F=1.396, \mathrm{df}=11,91, P=0.188 ; n=93$ cubs dying), and the number of cubs dying each month was unrelated to rainfall $(F=2.213, \mathrm{df}=1,100, P=0.140)$. Furthermore, for all cubs born within a given month, chi-squared comparison of those surviving $\geq 12$ months with those dying before 12 months revealed no significant variation among months of the year (chi-squared $=4.021 ; \mathrm{df}=10, P>0.50$ ). Thus, seasonal births in this spotted hyaena population did not appear to be influenced by patterns of cub mortality induced by heavy rains or other mortality sources. 

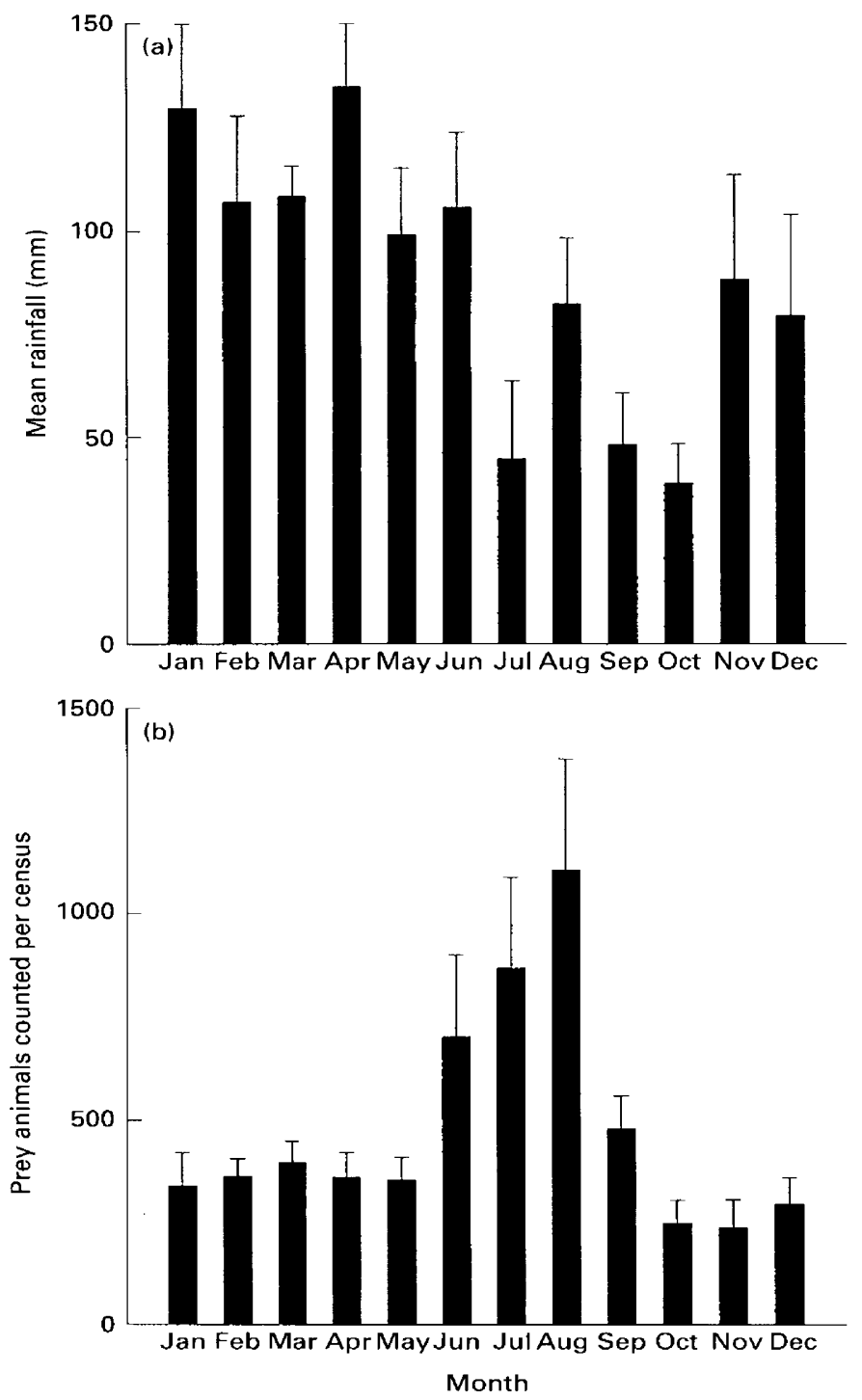

Fig. 2. Mean (+ SEM) monthly rainfall (a) and number of spotted hyaena prey animals counted per ungulate census (b) in the Talek study area, averaged over 10 years. Rainfall data were collected once a day and ungulate censuses were conducted two to four times per month.

\section{Relationships between prey abundance and reproductive parameters}

Prey availability was examined as a possible proximal determinant of reproductive seasonality in spotted hyaenas. The mean number of prey animals counted during ungulate censuses varied significantly from month to month (Fig. $2 \mathrm{~b}$; $F=4.648, \mathrm{df}=11,105, P<0.001)$. The annual influx of several thousand zebra and hundreds of thousands of wildebeest caused a marked increase in food availability for the hyaenas in this study population from June to September. The annual period of lowest prey abundance occurred during the months immediately after the departure of the migratory herds each fall, and prey densities did not then increase to moderate levels until rain stimulated renewed growth of local vegetation. When controlled for month of the year, neither the number of births (ANCOVA: $F=1.254, \mathrm{df}=4,106, P=0.293$ ) nor the number of weanings $(F=0.348, \mathrm{df}=4,103, P=0.845)$ per month was significantly correlated with prey abundance. However, after controlling for month of the year, a strong positive correlation was found between game abundance and the number of litters conceived each month (Fig. 3; $F=4.094$, $\mathrm{df}=4,109, P=0.004$ ). There was also a significant relationship between prey abundance and the percentage of females conceiving $\geq 7$ months after parturition $(F=7.037 ; \mathrm{df}=1,102$, $P=0.009$ ). Thus, seasonal changes in prey availability appeared to affect the likelihood of conception. There was no relationship between the number of conceptions and prey abundance during the preceding month $(F=0.025, \mathrm{df}=1,104$, $P=0.821$ ). These patterns suggest that female Crocuta are able to adjust rapidly their tendency to conceive new litters in response to changes in the food supply. 


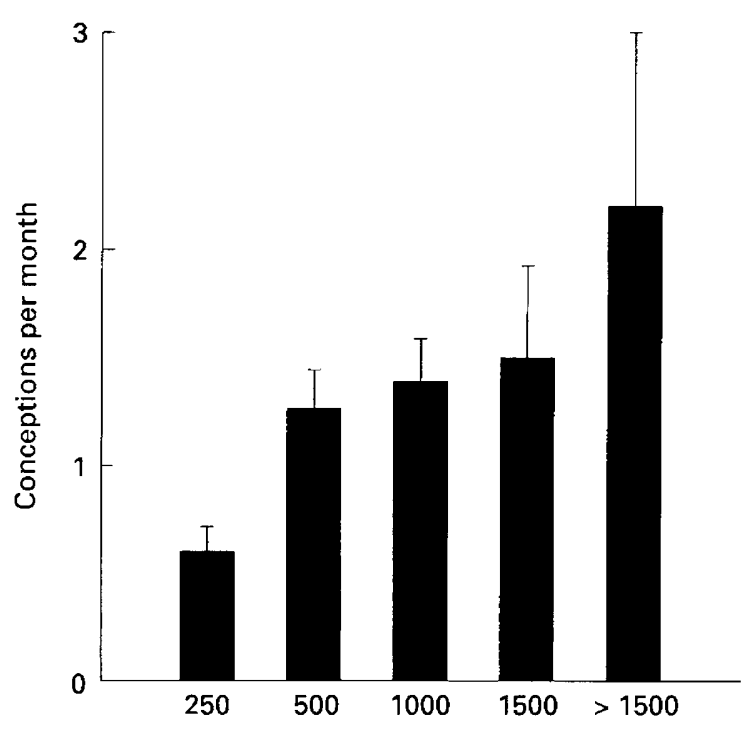

Prey animals counted per census

Fig. 3. Mean (+ SEM) number of hyaena conceptions occurring each month in relation to the mean number of prey animals counted per census during that month.

\section{Effects of weaning and parity of breeding females}

One proximate cause of the seasonal pattern of conceptions in this population could be seasonal changes in the cessation of lactational anoestrus. If this were the case, weaning should vary on a seasonal basis; however, this was not observed in the present study, in that the number of litters weaned did not vary significantly by month $(n=65$ litters: $F=1.045, \mathrm{df}=11,96, P=0.414$ ). The hypothesis proposed by Lindeque and Skinner (1982) that seasonal patterns of conception in spotted hyaenas are facilitated indirectly by seasonal increases in prey abundance that advance the time of weaning of previous litters and, as a consequence, advance the next oestrous period was also tested by comparing conceptions among parous females ( $n=94$ litters) with those among females bearing young for the first time ( $n=33$ litters). The seasonal pattern of conceptions among nulliparous females did not differ from that observed among parous females (chi-squared $=2.50$, $\mathrm{df}=10, P>0.50$ ), indicating that increased food availability increases directly the probability of conception in both groups of adult females, and that weaning of a previous litter alone is inadequate to explain the reproductive response of female hyaenas to altered prey abundance.

\section{Discussion}

Whereas a great deal is known about the social regulation of reproduction in tropical carnivores (for examples, see Malcolm and Marten, 1982; Creel et al., 1992; Holekamp et al., 1996; Creel and Waser, 1997; Moehlman and Hofer, 1997), little is known about the regulation of reproduction in these species by specific environmental factors (Bronson, 1989). The results of the present study, particularly when considered in light of data from other Crocuta populations, permit analysis of both proximal and ultimate explanations for the regulation of reproduction by environmental factors in spotted hyaenas. Although births occurred throughout the year in this equatorial hyaena study population, the annual pattern of births showed a distinct trough from February to May. In attempting to identify the proximal cues by which this seasonal pattern of reproduction is mediated, it was not possible to control any of the relevant environmental variables experimentally, but natural variation in these over time permitted elimination of some causal hypotheses. Because the study area was situated within $2^{\circ}$ of the equator, daylength varied by only a few minutes throughout the year. Thus, although it could not be ruled out as a possible cuing mechanism, it appears unlikely that reproductive seasonality in spotted hyaenas is cued by changing daylength as it is in various carnivore species living at higher latitudes (for examples, see Bissonnette, 1932; Dunn and Chapman, 1983; King, 1989). This notion is also supported by the observation of Kruuk (1972) that seasonal patterns of reproduction differ markedly among Crocuta populations inhabiting the Serengeti plains and Ngorongogo Crater, even though these two study areas are separated by $<1^{\circ}$ of latitude. That photoperiodic cues are unlikely to regulate reproduction even among Crocuta living at relatively high latitudes is suggested by the fact that births occur throughout the year at latitudes $25-28^{\circ} \mathrm{S}$, and that the number of births there do not vary significantly with month of the year (Mills, 1990).

Two ecological variables, rainfall and prey abundance, varied seasonally in the current study, although their annual patterns were not isomorphic. That is, the annual influx of migratory antelope occurred each year between June and August, when rainfall was relatively low. Although rainfall is used as a cue to stimulate seasonal reproduction in some tropical mammals, for example rodents (Delaney and Neal, 1969; Taylor and Green, 1976; Walker and Rabinowitz, 1992; ChandrasekarRao and Sunquist, 1996), rainfall could be ruled out as a proximal cue for Crocuta since there was no apparent relationship in the current study between rainfall and either births or conceptions. The hypothesis that Crocuta time their births to minimize cub deaths from flooded dens or other mortality sources could also be ruled out because cub deaths showed no significant seasonal variation.

The annual birth trough observed in the Talek study population occurred approximately one gestation period (3.6 months) after the phase of the annual cycle during which prey animals were least abundant in the home range of the study clan. Litters were least likely to be conceived when game was most scarce, indicating that prey availability has important effects on the timing of reproduction in Talek hyaenas. Furthermore, throughout the range of this species, it appears that reproductive seasonality occurs when prey abundance fluctuates seasonally, and peaks and troughs in the conception rate occur in conjunction with peaks and troughs, respectively, in local food abundance (Kruuk, 1972; Lindeque and Skinner, 1982; Mills, 1990; Cooper, 1993).

Although Crocuta occur from the equator to $28^{\circ}$ of latitude, no latitudinal cline in breeding season length is observed in this species as it is in various other mammals ranging from tropical to temperate zones (for example, Peromyscus spp, 
Bronson, 1989; Didelphis albiventris, Regidor and Gorostiague, 1996; Akodon azarae, Bilenca et al., 1994). Instead, seasonal patterns of local food availability appear to explain much of the variance observed among spotted hyaena populations with respect to reproductive seasonality. The present study is the first to maintain precise longitudinal demographic and reproductive records for a single population over a period of several years. Nevertheless, shorter term studies have revealed that reproductive seasonality is strongly pronounced in some populations of spotted hyaenas (for example, Cooper, 1993) while it is virtually absent in others (Deane 1962; Pienaar, 1963; Smithers, 1971; Eloff, 1975). Where previous investigators have presented concurrent data documenting both prey availability and female reproductive performance, a strong relationship has appeared between these variables. Lindeque and Skinner (1982) observed a distinct annual peak in the number of conceptions in southern Africa in December and January, which was also the period of peak food abundance. Mills (1990) observed a slight trough in births among Kalahari hyaenas between March and June, approximately one gestation period after the annual period of least game abundance in the area studied. As in the present study, seasonal patterns of prey abundance and rainfall were not isomorphic in the Kalahari. Among hyaenas inhabiting Ngorongoro Crater, Kruuk (1972) observed a peak in numbers of births in April each year, approximately one gestation period after the annual period of peak food abundance, during the wildebeest calving season. In Botswana, Cooper (1993) found that all Crocuta births occurred during the dry season, approximately one gestation period after the annual influx of several thousand migratory zebra.

Interlitter intervals are extremely variable in spotted hyaenas (Holekamp et al., 1996), and females appear to be prepared to breed at any time of year. Throughout the range of this species, it appears that reproductive seasonality is not promoted by a specific predictive cue in the environment, such as daylength or rainfall. Instead, seasonal reproduction in spotted hyaenas appears to be largely a consequence of seasonal changes in immediate availability of food. Crocuta obtain $65-95 \%$ of their total food intake from hunting medium and large sized ungulates (Kruuk, 1972; Mills, 1990; Holekamp et al., 1997; Cooper et al., 1999), so they rely heavily on local prey to satisfy their energetic and nutritional needs. Among Talek hyaenas, it appears that some minimum prey abundance may be necessary in the home range of the study clan for conceptions to occur regularly among females. When this minimal prey abundance is not reached, reproduction is inhibited. Thus, for female spotted hyaenas, food availability may function as both a proximal and an ultimate determinant of reproductive seasonality.

In various rodent species with gestation periods lasting only 2-4 weeks, energy shortages at the time of conception often reliably indicate that energy will also be in short supply during the lactation interval (for review, see Bronson, 1989), when energetic costs to breeding females are substantially higher than they are during gestation (for example, see Gittleman and Thompson, 1988; Clutton-Brock et al., 1989). However, because of the long gestation period in Crocuta, energy availability at conception is unlikely to indicate energy availability during lactation. Thus, female spotted hyaenas appear to decide whether to initiate new reproductive effort on the basis of information available to them at the time of conception. Efficient use of this information may reduce the likelihood of implantation failures or early embryo resorptions in spotted hyaenas.

Lindeque and Skinner (1982) suggested that the seasonal peak number they observed in hyaena conceptions in southern Africa was largely the consequence of cubs being weaned when prey were most abundant, and conceptions occurring soon after these weanings. However, this explanation cannot account for the seasonal pattern of hyaena reproduction found in the current study, in which, although conceptions varied significantly among months of the year, weanings did not. Moreover, the finding that primiparous and multiparous females did not differ with respect to their seasonal patterns of conceptions indicated that the timing of weaning is not responsible for reproductive seasonality in spotted hyaenas.

Overall, seasonal reproduction in spotted hyaenas appears to be a direct consequence of seasonal changes in the availability of energy or nutrients. That energy is likely to be a more important determinant of reproductive seasonality than specific nutrients is indicated by data collected from several other mammals examined in both the wild and in captivity (for review, see Bronson, 1989; Wade and Schneider, 1992; Schneider and Wade, in press). A body of research has confirmed that fertility is impaired when food intake is restricted. In all orders of mammals examined to date, ovulatory cycles are lengthened or interrupted by inadequate food intake, or by excessive energy expenditure that is not offset by compensatory increases in food intake (Bronson, 1989; I'Anson et al., 1991; Wade and Schneider, 1992; Foster, 1994; Wade et al., 1996; Schneider and Wade, in press).

In female laboratory rodents and livestock, chronic food restriction suppresses $\mathrm{GnRH}$ release and, hence, $\mathrm{LH}$ secretion, steroidogenesis and ovulation (for review, see Bronson, 1989; Foster, 1994). Thus, chronic food restriction retards reproductive development and suppresses the oestrous cycle. The mechanisms mediating the interaction between energy balance and endocrine control of reproduction in female mammals has received a great deal of recent attention (for example, see Morin, 1986; Bronson, 1989; Wade and Schneider, 1992). Temporal aspects of reproduction in various species of small mammal have been shown to be correlated with or affected by body mass, body fat stores and the availability of oxidizable metabolic fuels, such as fatty acids and glucose (French, 1982; Barnes, 1984; Bushberg and Holmes, 1985; Wade and Schneider, 1992), all of which are likely to vary with food availability. Similarly, the present data indicate that one of these physiological variables may be associated with seasonal changes in food abundance in Crocuta, and that this may mediate reproductive seasonality in spotted hyaenas.

The authors thank the Office of the President of Kenya for permission to conduct this research. They thank the Kenya Wildlife Service, the Narok County Council, and the Senior Warden of the 
Masai Mara National Reserve for their cooperation. They also thank the following individuals for their excellent assistance in the field: I. Graham, S. M. Cooper, C. I. Katona, N. E. Berry, K. Weibel, M. Durham, J. Friedman, G. Ording, T. H. Harty, P. Garrett, B. White, K. Nutt and R. Bankson. This work was supported by NSF grants BNS8706939, BNS9021461, IBN9296051, IBN9309805 and IBN9630667, and by fellowships to K. E. Holekamp from the David and Lucille Packard Foundation and from the Searle Scholars Program/Chicago Community Trust.

\section{References}

Altmann J (1974) Observational study of behavior: sampling methods Behaviour 49 227-267

Barnes BM (1984) Influence of energy stores on activation of reproductive function in male golden-mantled ground squirrels Journal of Comparative Physiology B 54 421-425

Bilenca DN, Zuleta GA and Kravetz FO (1994) Latitudinal variation in litter size and length of the breeding season in populations of pampas mice, Akodon azarae. Mammalia 58 563-568

Bissonnette TH (1932) Modifications of mammalian sexual cycles: reactions of ferret (Putoris vulgaris) of both sexes to electric light added in November and December Proceedings of the Royal Society, London Series B 110332-336

Bronson FH (1989) Mammalian Reproductive Biology University of Chicago Press, Chicago

Bushberg DM and Holmes WG (1985) Sexual maturation in male Belding's ground squirrels: influence of body weight Biology of Reproduction 33 302-308

ChandrasekarRao A and Sunquist ME (1996) Ecology of small mammals in tropical forest habitats of southern India Journal of Tropical Ecology 12 561-571

Clutton-Brock TH, Albon SD and Guiness FE (1989) Fitness costs of gestation and lactation in wild mammals Nature $337260-262$

Cooper SM (1993) Denning behaviour of spotted hyaenas (Crocuta crocuta) in Botswana African Journal of Ecology 31 178-180

Cooper SM, Holekamp KE and Smale L (1999) A seasonal feast: long-term analysis of feeding behaviour in the spotted hyaena Crocuta crocuta (Erxleben) African Journal of Ecology 37 149-160

Creel S, Creel N, Wildt DE and Monfort SL (1992) Behavioral and endocrine mechanisms of reproductive suppression in Serengeti dwarf mongooses Animal Behavior 43 231-245

Creel SR and Waser PM (1997) Variation in reproductive suppression among dwarf mongooses: interplay between mechanisms and evolution. In Cooperative Breeding in Mammals pp 150-170 Eds NG Solomon and JA French. Cambridge University Press, Cambridge

Deane NN (1962) The spotted hyaena Crocuta crocuta. Lammergeyer 2 131-141

Delany MJ and Neal BR (1969) Breeding seasons of rodents in Uganda Journal of Reproduction and Fertility Supplement 6229-235

Dunn JP and Chapman JA (1983) Reproduction, physiological responses, age structure and food habits of racoons in Maryland, USA Zeitschrift fur Saugetierkunde 48 161-175

East ML, Hofer H and Wickler W (1993) The erect 'penis' as a flag of submission in a female-dominated society: greetings in Serengeti spotted hyaenas Behavioral Ecology and Sociobiology 33 355-370

Eloff FC (1975) The spotted hyaena Crocuta crocuta (Erxleben) in arid regions of southern Africa Publications of the University of Pretoria 97 35-39

Estes RD (1991) The Behavior Guide to African Mammals University of California Press, Berkeley and Los Angeles

Foster DL (1994) Puberty in sheep. In The Physiology of Reproduction 2nd Edn pp 411-451. Eds E Knobil and JD Neill. Raven Press, New York

Frank LG (1986) Social organisation of the spotted hyaena (Crocuta crocuta) I. Demography Animal Behavior 35 1500-1509

Frank LG and Glickman SE (1994) Giving birth through a penile clitoris: parturition and dystocia in the spotted hyaena, Crocuta crocuta. Journal of Zoology, London 234 659-665
Frank LG, Glickman SE and Powch I (1990) Sexual dimorphism in the spotted hyaena Journal of Zoology, London 221 308-313

French AR (1982) Intraspecific differences in the pattern of hibernation in the ground squirrel Spermophilus beldingi. Journal of Comparative Physiology 148 83-91

Gittleman JL and Thompson SD (1988) Energy allocation in mammalian reproduction American Zoologist 28 863-875

Holekamp KE, Ogutu JO, Dublin HT, Frank LG and Smale L (1993) Fission of a spotted hyaena clan: consequences of prolonged female absenteeism and causes of female emigration Ethology 93 285-299

Holekamp KE, Smale L and Szykman M (1996) Rank and reproduction in female spotted hyenas Journal of Reproduction and Fertility 108 229-237

Holekamp KE, Smale L and Cooper SM (1997) Hunting rates and hunting success in the spotted hyaena Journal of Zoology, London 242 1-15

I'Anson H, Foster DL, Foxcroft CR and Booth PJ (1991) Nutrition and reproduction Oxford Reviews of Reproductive Biology 13 239-311

King C (1989) The Natural History of Weasels and Stoats Cornell University Press, Ithaca, NY

Kruuk H (1972) The Spotted Hyaena: a Study of Predation and Social Behavior University of Chicago Press, Chicago

Lindeque $M$ and Skinner JD (1982) A seasonal breeding in the spotted hyaena Crocuta crocuta in southern Africa African Journal of Ecology 20 271-278

Malcolm JR and Marten K (1982) Natural selection and the communal rearing of pups in the African wild dog (Lycaon pictus) Behavioral Ecology and Sociobiology 10 1-13

Mills MGL (1990) Kalahari Hyaenas: The Behavioural Ecology of Two Species Unwin Hyman, London

Moehlman PD and Hofer H (1997) Cooperative breeding, reproductive suppression, and body mass in canids. In Cooperative Breeding in Mammals pp 76-128 Eds NG Solomon and JA French. Cambridge University Press, Cambridge

Morin LP (1986) Environment and hamster reproduction: responses to phasespecific starvation during the estrous cycle American Journal of Physiology 251 R663-R669

Pienaar U de V (1963) The large mammals of the Kruger National Park, their distribution and present day status Koedoe 6 1-37

Regidor HA and Gorostiague M (1996) Reproduction in the white eared opossum (Didelphis albiventris) under temperate conditions in Argentina Studies on Neotropical Fauna and Environment 31 133-136

Schneider KM (1926) Uber Hyaenenzucht Die Pelztierzucht 21-14

Schneider JE and Wade GN Inhibition of reproduction in service of energy balance. In Reproduction in Context: Environmental and Social Influences on Reproductive Physiology and Behavior Eds K Wallen and JE Schneider. MIT Press, Cambridge, MA (in press)

Sinclair ARE (1979) The Serengeti environment. In Serengeti: Dynamics of an Ecosystem pp 31-34 Eds ARE Sinclair and M Norton-Griffiths. University of Chicago Press, Chicago

Sinclair ARE (1995) Serengeti past and present. In Serengeti II: Dynamics, Management and Conservation of an Ecosystem pp 3-30 Eds ARE Sinclair and $P$ Arcese. University of Chicago Press, Chicago

Smale L, Nunes S and Holekamp KE (1997) Sexually dimorphic dispersal in mammals: patterns, causes and consequences Advances in the Study of Behavior 26 181-250

Smithers RHN (1966) The Mammals of Rhodesia, Zambia and Malawi Collins, London

Smithers RHN (1971) The Mammals of Botswana Museum Memoire number 4 Trustees of the National Museums and Monuments of Rhodesia, Salisbury

Taylor KD and Green MG (1976) The influence of rainfall on diet and reproduction on four African rodent species Journal of Zoology, London 180 367-389

Wade GN and Schneider JE (1992) Metabolic fuels and reproduction in female hamsters Neuroscience and Biobehavioral Reviews 16 235-272

Wade GN, Schneider JE and Li H-Y (1996) Control of fertility by metabolic cues American Journal of Physiology 270 E1-E19

Walker S and Rabinowitz A (1992) The small mammal community of a dry tropical forest in central Thailand Journal of Tropical Ecology 857-71 